\title{
Immune Response to Standard Hepatitis B Vaccination in HIV-Infected Patients
}

\author{
Amitis Ramezani $^{1}$, Minoo Mohraz ${ }^{2}$, Mohammad Banifazl $^{3}$, Maryam Foroughi $^{2}$, Ali Eslamifar ${ }^{1}$, Arezoo Aghakhani $^{{ }^{*}}$
}

\author{
1 Department of Clinical Research, Pasteur Institute of Iran, Tehran, Iran. \\ 2 Iranian Research Center for HIV/AIDS, Tehran, Iran. \\ 3 Iranian Society for Support of Patients with Infectious Diseases, Tehran, Iran.
}

Accepted Mar 02, 2015

\begin{abstract}
Introduction: Due to their similar routes of transmission, human immunodeficiency virus (HIV) and hepatitis B virus (HBV) co-infection occurs considerably. HBV infection progresses more rapidly in HIV-infected patients. Therefore, HBV vaccination of all non-immune HIV infected patients is recommended. On the other hand, HIVinfected subjects have suboptimal responses to HBV vaccine. In this study, we aimed to determine the immune responses to standard HBV vaccination in HIV-infected patients. Methods: Fifty-six HIV infected patients who lacked evidence of either prior HBV infection or immunity were subjected to standard HBV vaccination, as 3 intramuscular injections of the standard dose $(20 \mu \mathrm{g})$ of recombinant $\mathrm{HBV}$ vaccine at months 0,1 and 6 . Hepatitis B surface antibody (anti-HBs) titers were checked in all cases one month after the vaccination. A protective antibody response was defined as an anti-HBs titer of $\geq 10 \mathrm{IU} / \mathrm{L}$. Results: HBV seroprotection was observed in $56.6 \%$ of HIV-infected patients. There was no significant difference between cases with and without seroprotection regarding age, sex, possible route of HIV acquisition, CD4 count, receiving antiretroviral therapy (and its duration) and HCV infection. Conclusion: Our study confirms previous reports that HIV-infected patients have a lower response rate to the standard HBV vaccination compared to general population. So other strategies are needed to improve the HBV vaccine response rate in HIV cases.
\end{abstract}

KEYWORDS: Human Immunodeficiency Virus(HIV), Hepatitis B Virus(HBV), Vaccination.

\section{INTRODUCTION}

Due to the similar routes of transmission and risk factors, the rate of human immunodeficiency virus (HIV) and hepatitis B virus (HBV) co-infection is considerable [1-3]. Chronic HBV infection affects approximately $10 \%$ of HIV-infected subjects throughout the world, with higher rates in high $\mathrm{HBV}$ endemicity areas and in high risk groups such as injecting drug users [2-4]. HBV infection progresses more rapidly in HIVinfected patients, with higher rates of HBV viremia, HBV reactivation, cirrhosis and hepatocellular carcinoma [5]. HBV infection has been also associated with more rapid progression of HIV infection to AIDS, by an increased expression of HIVinfected cells and a faster decrease in CD4 lymphocytes [6,7]. Moreover, the risk of hepatotoxicity from highly active antiretroviral therapy (HAART) increases in HIV/HBV coinfected patients $[4,8]$. Therefore according to the current guidelines, HBV vaccine is highly recommended to all asymptomatic HIV-infected patients without evidence of prior HBV infection or the immunity to HBV, $[9,10]$.

In healthy adults, HBV vaccination is associated with a good

*Corresponding Author: Arezoo Aghakhani, Ph.D; Clinical Research Dept. Pasteur Institute of Iran, Tehran, Iran. No. 69, Pasteur Ave, Tehran, Iran, 1316943551.

Email: araghakhani@hotmail.com

Tel: (+98) 2166465147 , Fax: (+98) 2166968852 protection against $\mathrm{HBV}$ infection and has a seroconversion rate of more than $90 \%[11,12]$. Due to the impaired immune responses, the success rate of HBV vaccination is lower in HIV-infected cases compared to the general population, with immunogenicity rates varying from $17.5 \%$ to $72 \%$ [13-15]. The risk factors for lower rate of responses to $\mathrm{HBV}$ vaccine included higher HIV viral load, hepatitis C virus antibody (anti-HCV) positivity and lower CD4 cell count prior to the vaccination [14, 16-19]. Meanwhile, achieving seroprotection rates of $\mathrm{HBV}$ vaccine in $\mathrm{HIV}$-infected patients remains a challenge. Due to the importance of HBV prophylaxis in highrisk groups, particularly HIV infected patients; we aimed to determine the immune responses to standard HBV vaccination in HIV-infected patients and its relation to different variables such as age, sex, route of HIV acquisition and the immune status.

\section{MATERIALS and METHODS}

In this cross-sectional study, HIV-infected patients from Iranian Research Center for HIV/AIDS in Tehran were enrolled from March to September 2014. This project was approved by the Ethics Committee of Pasteur Institute of Iran and informed consents were obtained from the patients prior to their enrollments. A questionnaire that gathered 
epidemiological, clinical and laboratory data was completed by the clinicians.

Human immunodeficiency virus antibody (anti-HIV) was determined by ELISA (MP Biomedicals, Illkirch, France) and the positive tests were confirmed by Western blot assays (Diaplus, San Francisco, USA).

All samples were tested for hepatitis B surface antigen (HBsAg), Hepatitis B surface antibody (anti-HBs), Hepatitis B core antibody (anti-HBc) and anti-HCV by ELISA. The commercial enzyme immunoassay kits used were as follows: HBsAg (Hepanosticka Biomerieux, Boxtel, the Netherlands), anti-HBs (Enzygnost, Dade Behring Marburg $\mathrm{GmbH}$, Germany), anti-HBc (Enzygnost, Dade Behring Marburg $\mathrm{GmbH}$, Germany) and anti-HCV (Biorad, Segrate, Italy). Recombinant immunoblot assay (RIBA Innogenetics, Ghent, Belgium) was employed to confirm anti-HCV reactivity.

Fifty-six HIV infected patients who lacked evidence of either prior HBV infection or immunity to the infection were subjected to standard HBV vaccination [3 intramuscular injections of the standard dose $(20 \mu \mathrm{g})$ of recombinant HBV vaccine (Pasteur Institute of Iran, Tehran, Iran) at months 0, 1 and 6]. Anti-HBs titers were checked in all cases one month after the vaccination by ELISA. A protective antibody response was defined as an anti-HBs titer $\geq 10 \mathrm{IU} / \mathrm{L}$.

\section{Statistical Analysis}

The chi-square test was used with SPSS 16 package program for statistical analysis (Chicago, IL, USA). Data are presented as mean $\pm \mathrm{SD}$ or when indicated, as an absolute number and percentage.

\section{RESULTS}

In this study, 56 HIV-infected patients were enrolled. The mean age of the patients was $36.91 \pm 7$ years. Among them, $53.6 \%$ were male and $46.4 \%$ were female. The mean CD 4 count of the HIV subjects was $467.54 \pm 218.93$ cells $/ \mathrm{mm}^{3}$. The presumed routes of HIV transmission were heterosexual contact $(53.6 \%)$, intravenous drug use $(41.1 \%)$, infected blood and blood products transfusion $(1.8 \%)$, and in $3.6 \%$ of the cases, the route of HIV acquisition was not identified. Patients who had received antiretroviral therapy (ART) were $98.1 \%$ and the mean duration of their ART was $32.5 \pm 21.05$ months. The anti-HCV positives were $69.6 \%$ of the cases. HBV seroprotection was observed in $56.6 \%$ of the HIV-infected patients. There was no significant difference between the cases with or without seroprotection, with regard to sex, possible route of HIV acquisition, CD4 count, receiving ART, duration of their ART and HCV infection.

\section{DISCUSSION}

The present study investigated the immune responses to standard HBV vaccination in HIV-infected patients and its relation to different variables. We found a response rate of $56.6 \%$ in HIV-infected patients. Our survey showed a lower rate of HBV seroprotection after standard HBV vaccination in case of infected people with HIV, compared to the general population, regardless of their age, sex, possible route of HIV acquisition, CD4 count, receiving ART (and its duration) and HCV infection. Approximately $90-97 \%$ of healthy adults will show protective anti-HBs titers after vaccination with recombinant $\mathrm{HBV}$ vaccine $[11,12]$. It is recommended that all HIV positive adults be screened for prior HBV infection. Any person who is, HBsAg, anti-HBs and anti-HBc negative should receive the three-dose $\mathrm{HBV}$ vaccination series, regardless of his/her CD4 count or HIV viral load [20, 21]. Prior studies of the immune responses to HBV vaccine in HIV infected patients have indicated varying response rates from $0 \%$ to $87 \%$. [15, 16 , $18,19,22-25]$.

Cornejo-Juárez et al. [26] found $60.7 \%$ response rate in HIVinfected patients vaccinated with HBV recombinant vaccine. In Bailey et al. study [27], the response rate to HBV vaccination was $47 \%$. Higher CD4 counts and lower HIV viral loads were significantly associated with seroconversion. In another investigation by Paitoonpong et al. [28], the overall response rate to HBV vaccination was $71.4 \%$. The responder group had a significantly higher CD4 counts than the non-responder group. In a survey in Iran on 48 HIV-positive patients, 29.1\% of the vaccinated HIV-infected patients had positive anti-HBs titers [29]. In another study performed in Kermanshah, Iran, HBV immune responses were detected in $52.7 \%$ of the cases [30]. Studies comparing seroprotection rate of standard hepatitis B vaccination in HIV-positive patients were shown in Table 1. The association of HBV seroprotection rates and CD4 counts is controversial. Some studies have shown higher response rates associated with higher CD4 counts while others have obtained contrary data $[15,16,18,19,22-25]$. Our study showed that CD4 counts had no influence on the immune response to $\mathrm{HBV}$ vaccination and accords with Wilson [16] and Overton [22] studies.

Table. 1. Studies comparing seroprotection rates of standard Hepatitis $B$ vaccination in HIV-positive patients.

\begin{tabular}{|c|c|}
\hline Publications & Seroprotection Rates \\
\hline Collier et al. (1988) [24] & $\begin{array}{l}\text { CD4 >500: } 87.5 \% \\
\text { CD4 <500: } 33.2 \%\end{array}$ \\
\hline Hess et al. (1989) [23] & $0 \%$ \\
\hline Rey et al. (2000) [15] & $\begin{array}{l}\text { CD4 >500: } 87.5 \% \\
\text { CD4 200-500: } 33.3 \%\end{array}$ \\
\hline Wilson et al. (2001) [22] & $37.1 \%$ \\
\hline Alaei et al.(2003) [29] & $29.1 \%$ \\
\hline Tedaldi et al. (2004) [19] & $37.2 \%$ \\
\hline Gandhi et al. (2005) [18] & $62.3 \%$ \\
\hline Overton et al. (2005) [16] & $17.5 \%$ \\
\hline Fonseca et al.(2005) [13] & $34 \%$ \\
\hline Cornejo-Juárez et al. (2006) [26] & $60.7 \%$ \\
\hline Janbakhsh et al. (2006) [30] & $52.7 \%$ \\
\hline Veiga et al. (2006) [31] & $59 \%$ \\
\hline Ungulkraiwit et al. (2007) [32] & $46 \%$ \\
\hline Bailey et al.(2008) [27] & $47 \%$ \\
\hline Paitoonpong et al.(2008) [28] & $71.4 \%$ \\
\hline Landrum et al. (2009) [33] & $35 \%$ \\
\hline Psevdos et al. (2010) [34] & $34.7 \%$ \\
\hline Launay et al.(2011) [35] & $65 \%$ \\
\hline Kaech et al. (2012) [36] & $22 \%$ \\
\hline
\end{tabular}

In this study, there was no significant difference in response rates to $\mathrm{HBV}$ vaccination in cases with or without $\mathrm{HCV}$ coinfection, as shown in other studies [30, 36]. However, few studies have indicated that $\mathrm{HCV}$ infection can reduce the responsiveness to HBV vaccination [18]. These discrepancies may be due to the different rates of HCV co-infection in the studied subjects. The lack of association between age or gender and HBV vaccine responsiveness was not unexpected which was in accordance with some previous studies [30, 37]. The association between the HBV vaccine response rates and antiretroviral therapy and its duration has been shown in some 
studies [2, 30]; however, other investigations have failed to establish a link between these variables and HBV vaccine seroprotection $[32,38]$. We also could not find the influence of antiretroviral therapy and its duration on the immune response rate to HBV vaccine. A major limitation of our study was the relatively small sample sizes which might have led to the nonsignificant results of the variables. In conclusion, our study confirms the previous reports that had indicated HIV-infected patients have a lower response rate to the standard HBV vaccination, compared to the general population. So, other strategies such as increasing the number of HBV immunizations, higher vaccine doses or use of different vaccination routes need to improve the HBV vaccine response rate in HIV cases.

\section{ACKNOWLEDGEMENTS}

The authors are grateful to Pasteur Institute of Iran for financial support of this study.

\section{CONFLICT OF INTEREST:}

All of the authors have declared that no competing interests exist.

\section{REFERENCES}

1. Konopnicki D, Mocroft A, de Wit S, Antunes F, Ledergerber B, Katlama C et al. Hepatitis B and HIV: prevalence, AIDS progression, response to highly active antiretroviral therapy and increased mortality in the EuroSIDA cohort. Aids. 2005;19(6):593-601.

2. Kellerman SE, Hanson DL, McNaghten AD, Fleming PL. Prevalence of chronic hepatitis B and incidence of acute hepatitis B infection in human immunodeficiency virus-infected subjects. The Journal of infectious diseases. 2003;188(4):571-7. doi:10.1086/377135.

3. Thio CL, Seaberg EC, Skolasky R, Jr., Phair J, Visscher B, Munoz A et al. HIV-1, hepatitis B virus, and risk of liver-related mortality in the Multicenter Cohort Study (MACS). Lancet. 2002;360(9349):1921-6.

4. Puoti M, Airoldi M, Bruno R, Zanini B, Spinetti A, Pezzoli C et al. Hepatitis $\mathrm{B}$ virus co-infection in human immunodeficiency virus-infected subjects. AIDS reviews. 2002;4(1):27-35.

5. Grob P, Jilg W, Bornhak H, Gerken G, Gerlich W, Gunther S et al. Serological pattern "anti-HBc alone": report on a workshop. Journal of medical virology. 2000;62(4):450-5.

6. Eskild A, Magnus P, Petersen G, Sohlberg C, Jensen F, Kittelsen P et al. Hepatitis B antibodies in HIV-infected homosexual men are associated with more rapid progression to AIDS. Aids. 1992;6(6):571-4.

7. Horvath J, Raffanti SP. Clinical aspects of the interactions between human immunodeficiency virus and the hepatotropic viruses. Clinical infectious diseases : an official publication of the Infectious Diseases Society of America. 1994;18(3):339-47.

8. Sulkowski MS, Thomas DL, Chaisson RE, Moore RD. Hepatotoxicity associated with antiretroviral therapy in adults infected with human immunodeficiency virus and the role of hepatitis $\mathrm{C}$ or $\mathrm{B}$ virus infection. Jama. 2000;283(1):74-80.

9. Masur H, Kaplan JE, Holmes KK, Service USPH, Infectious Diseases Society of A. Guidelines for preventing opportunistic infections among HIV-infected persons--2002. Recommendations of the U.S. Public Health Service and the Infectious Diseases Society of America. Annals of internal medicine. 2002;137(5 Pt 2):435-78.

10. Laurence JC. Hepatitis A and B immunizations of individuals infected with human immunodeficiency virus. The American journal of medicine. 2005;118 Suppl 10A:75S-83S. doi:10.1016/j.amjmed.2005.07.024.

11. Fitzsimons D, Francois G, Hall A, McMahon B, Meheus A, Zanetti A et al. Long-term efficacy of hepatitis B vaccine, booster policy, and impact of hepatitis B virus mutants. Vaccine. 2005;23(32):4158-66. doi:10.1016/j.vaccine.2005.03.017.

12. Floreani A, Baldo V, Cristofoletti M, Renzulli G, Valeri A, Zanetti C et al. Long-term persistence of anti-HBs after vaccination against HBV: an 18 year experience in health care workers. Vaccine. 2004;22(5-6):607-10.
13. Fonseca MO, Pang LW, de Paula Cavalheiro N, Barone AA, Heloisa Lopes M. Randomized trial of recombinant hepatitis B vaccine in HIVinfected adult patients comparing a standard dose to a double dose. Vaccine. 2005;23(22):2902-8. doi:10.1016/j.vaccine.2004.11.057.

14. Kim HN, Harrington RD, Van Rompaey SE, Kitahata MM. Independent clinical predictors of impaired response to hepatitis B vaccination in $\mathrm{HIV}$-infected persons. International journal of STD \& AIDS. 2008;19(9):600-4. doi:10.1258/ijsa.2007.007197.

15. Rey D, Krantz V, Partisani M, Schmitt MP, Meyer P, Libbrecht E et al. Increasing the number of hepatitis B vaccine injections augments anti-HBs response rate in HIV-infected patients. Effects on HIV-1 viral load. Vaccine. 2000;18(13):1161-5.

16. Overton ET, Sungkanuparph S, Powderly WG, Seyfried W, Groger RK, Aberg JA. Undetectable plasma HIV RNA load predicts success after hepatitis B vaccination in HIV-infected persons. Clinical infectious diseases : an official publication of the Infectious Diseases Society of America. 2005;41(7):1045-8. doi:10.1086/433180.

17. Quaglio G, Talamini G, Lugoboni F, Lechi A, Venturini L, Jarlais DC et al. Compliance with hepatitis B vaccination in 1175 heroin users and risk factors associated with lack of vaccine response. Addiction. 2002;97(8):985-92.

18. Gandhi RT, Wurcel A, Lee H, McGovern B, Shopis J, Geary M et al. Response to hepatitis B vaccine in HIV-1-positive subjects who test positive for isolated antibody to hepatitis B core antigen: implications for hepatitis B vaccine strategies. The Journal of infectious diseases. 2005;191(9):1435-41. doi:10.1086/429302.

19. Tedaldi EM, Baker RK, Moorman AC, Wood KC, Fuhrer J, McCabe $\mathrm{RE}$ et al. Hepatitis A and $\mathrm{B}$ vaccination practices for ambulatory patients infected with HIV. Clinical infectious diseases : an official publication of the Infectious Diseases Society of America. 2004;38(10):1478-84. doi:10.1086/420740.

20. Achievements in public health: hepatitis B vaccination-United States, 1982-2002. Centers for Disease Control and Prevention. MMWR Morb Mortal Wkly Rep. 2002; 51:549-52.

21. A comprehensive immunization strategy to eliminate transmission of hepatitis B virus infection in the United States. Recommendations of the Advisory Committee on Immunization Practices (ACIP) part II immunization of adults. Centers for Disease Control and Prevention. MMWR Morb Mortal Wkly Rep. 2006; 55(RR-16):1-31.

22. Wilson CM, Ellenberg JH, Sawyer MK, Belzer M, Crowley-Nowick PA, Puga A et al. Serologic response to hepatitis B vaccine in HIV infected and high-risk HIV uninfected adolescents in the REACH cohort. Reaching for Excellence in Adolescent Care and Health. The Journal of adolescent health : official publication of the Society for Adolescent Medicine. 2001;29(3 Suppl):123-9.

23. Hess G, Rossol S, Voth R, Cheatham-Speth D, Clemens R, Meyer zum Buschenfelde KH. Active immunization of homosexual men using a recombinant hepatitis $B$ vaccine. Journal of medical virology. 1989;29(4):229-31.

24. Collier AC, Corey L, Murphy VL, Handsfield HH. Antibody to human immunodeficiency virus (HIV) and suboptimal response to hepatitis B vaccination. Annals of internal medicine. 1988;109(2):101-5.

25. Wong EK, Bodsworth NJ, Slade MA, Mulhall BP, Donovan B. Response to hepatitis B vaccination in a primary care setting: influence of HIV infection, CD4+ lymphocyte count and vaccination schedule. International journal of STD \& AIDS. 1996;7(7):490-4.

26. Cornejo-Juárez P, Volkow-Fernández P, Escobedo-López K, Vilar-Compte D, Ruiz-Palacios G, Soto-Ramírez LE. Randomized controlled trial of Hepatitis B virus vaccine in HIV-1-infected patients comparing two different doses. AIDS Res Ther. 2006; 6; 3:9. 27. Bailey CL, Smith V, Sands M. Hepatitis B vaccine: a seven-year study of adherence to the immunization guidelines and efficacy in HIV-1positive adults. International journal of infectious diseases : IJID : official publication of the International Society for Infectious Diseases 2008;12(6):e77-83. doi:10.1016/j.ijid.2008.05.1226.

28. Paitoonpong L, Suankratay C. Immunological response to hepatitis B vaccination in patients with AIDS and virological response to highly active antiretroviral therapy. Scandinavian journal of infectious diseases. 2008;40(1):54-8. doi:10.1080/00365540701522975

29. Alaei K, Mansoori D, Alaei A. The response to Hepatitis B virus vaccination in HIV-infected patients. Arch Iranian Med. 2003;6(4): 269-72.

30. Janbakhsh A, Vaziri S, Sayad B, Afsharian M, Rezaei M, Montazeripour H. Immune Response to Standard Dose of Hepatitis B Vaccine in HIV Positive Clients of Kermanshah Behavioral Diseases Counseling Center. Hepat Mon. 2006;6(2):71-4. 
31. Veiga AP, Casseb J, Duarte AJ. Humoral response to hepatitis B vaccination and its relationship with $\mathrm{T} C \mathrm{CD} 45 \mathrm{RA}+$ (naive) and CD45RO+ (memory) subsets in HIV-1-infected subjects. Vaccine. 2006;24(4950):7124-8. doi:10.1016/j.vaccine.2006.06.079.

32. Ungulkraiwit P, Jongjirawisan Y, Atamasirikul K, Sungkanuparph S. Factors for predicting successful immune response to hepatitis B vaccination in HIV-1 infected patients. The Southeast Asian journal of tropical medicine and public health. 2007;38(4):680-5.

33. Landrum ML, Hullsiek KH, O'Connell RJ, Chun HM, Ganesan A, Okulicz JF et al. Hepatitis B vaccine antibody response and the risk of clinical AIDS or death. PloS one. 2012;7(3):e33488. doi:10.1371/journal.pone.0033488.

34. Psevdos G, Kim JH, Groce V, Sharp V. Efficacy of double-dose hepatitis B rescue vaccination in HIV-infected patients. AIDS patient care and STDs. 2010;24(7):403-7. doi:10.1089/apc.2009.0340.

35. Launay O, van der Vliet D, Rosenberg AR, Michel ML, Piroth L, Rey
D et al. Safety and immunogenicity of 4 intramuscular double doses and 4 intradermal low doses vs standard hepatitis B vaccine regimen in adults with HIV-1: a randomized controlled trial. Jama. 2011;305(14):1432-40. doi:10.1001/jama.2011.351.

36. Kaech C, Pache I, Burgisser P, Elzi L, Darling KE, Cavassini M. Immune response to hepatitis B vaccination in HIV-positive adults with isolated antibodies to $\mathrm{HBV}$ core antigen. The Journal of infection 2012;65(2):157-64. doi:10.1016/j.jinf.2012.03.009.

37. Sasaki M, Foccacia R, de Messias-Reason IJ. Efficacy of granulocytemacrophage colony-stimulating factor (GM-CSF) as a vaccine adjuvant for hepatitis $B$ virus in patients with HIV infection. Vaccine. 2003;21(31):4545-9.

38. Potsch DV, Oliveira ML, Ginuino C, Miguel JC, Oliveira SA, Silva EF et al. High rates of serological response to a modified hepatitis $B$

vaccination schedule in $\mathrm{HIV}$-infected adults subjects. Vaccine. 2010;28(6):1447-50. doi:10.1016/j.vaccine.2009.11.066. 